\title{
Educação Matemática Realística: Uma Abordagem para o Ensino e a Avaliação em Matemática
}

\author{
Realistic Mathematics Education: An Approach to Teaching and \\ Assessment in Mathematics
}

\author{
André Luis Trevisan \\ andretrevi@yahoo.com.br \\ Regina Luzia Corio de Buriasco \\ reginaburiasco@gmal.com
}

\begin{abstract}
Resumo
Neste artigo, apresentamos algumas características da Educação Matemática Realística (RME), abordagem para o ensino da Matemática respaldada nas ideias do matemático Hans Freudenthal. Discutimos a concepção de avaliação atrelada a essa abordagem, cuja finalidade é coletar dados dos estudantes e de seus processos de aprendizagem, a fim de tomar decisões educacionais. Além disso, analisamos também o papel desempenhado pelas tarefas ou problemas escolhidos para avaliação, sendo que estes deveriam possibilitar aos estudantes demonstrar o que sabem mais do que simplesmente revelar o que ainda não sabem. Por fim, relatamos o modo como a RME “inspirou-nos” a repensar nossa própria prática avaliativa e atitudes enquanto professor.
\end{abstract}

Palavras-chave: Educação Matemática. Educação Matemática Realística. Avaliação da aprendizagem. Prova em fases. Prática reflexiva.

\begin{abstract}
In this article, we present some characteristics in Realistic Mathematical Education (RME), which is an approach to Mathematics teaching based on the ideas of the Mathematician Hans Freudenthal. It is discussed the conception of assessment based on this approach, whose aim is to gather data from students and their learning processes to make educational decisions. Moreover, it was also analyzed the role of the tasks and the problems chosen for evaluation, considering that these should enable the students to demonstrate that they know more than simply unveil what they do not know yet. Finally, it is reported the way RME inspired us to rethink our own assessment practice and the attitudes as a teacher.
\end{abstract}

Keywords: Mathematics Education. Realistic Mathematics Education. Learning assessment. Stage task. Reflexive practice.

\section{Introdução}

O movimento conhecido como Educação Matemática Realística (RME, do inglês Realistic Mathematics Education), que tem como precursor o matemático Hans Freudenthal, tem suas origens na Holanda no final da década de 1960. Opondo-se ao formalismo apregoado pelos partidários da Matemática Moderna, a RME entende matemática como uma atividade natural e social cuja evolução acompanha a do indivíduo e a das necessidades de um mundo em expansão. 
Muita embora cerca de 50 anos tenham se passado desde sua implantação até os dias atuais, a RME é ainda pouco divulgada no Brasil. O levantamento realizado por Ferreira et al (2012) mostrou que até o ano de 2010 praticamente não haviam sido publicados no trabalhos (incluindo teses, dissertações, artigos em anais de eventos e em periódicos) que abordassem o tema.

Esse texto apresenta alguns apontamentos acerca da RME, tanto como forma de divulga-la à comunidade brasileira de pesquisadores e professores que ensinam Matemática, quanto como desafio (talvez um pouco pretencioso, confessemos), de sintetizar aquelas que julgamos serem as ideias principais que a sustentam. Nosso interesse justifica-se por a considerarmos uma abordagem que vai ao encontro de nossas ideias acerca de como deveria ser o ensino da Matemática. Discutimos também a concepção de avaliação atrelada a essa abordagem, cuja finalidade é coletar dados dos estudantes e de seus processos de aprendizagem, a fim de tomar decisões educacionais. Analisamos o papel desempenhado pelas tarefas ou problemas escolhidos para avaliação: possibilitar aos estudantes demonstrar o que sabem mais do que simplesmente revelar o que ainda não sabem. Por fim, relatamos o modo como a RME "inspirou-nos" a repensar nossa própria prática avaliativa e atitudes enquanto professor.

\section{Matemática como atividade humana}

Segundo Freudenthal (1979, p. 317), no fim dos anos 50, “a agitação criada pelo Sputnik deu origem a uma discussão a respeito do ensino da Matemática e das Ciências tal como era praticado", o que culminou com a formulação de inúmeras propostas que foram concretizadas em novos materiais escolares, e "baptizou-se este conjunto de 'Matemática Moderna"”.

Entretanto, a euforia dos anos 60 deu origem ao desencantamento dos anos 70. Afinal,

pobres professores, incapazes de acompanhar o movimento, eram obrigados a aprender e, em seguida, ensinar aos outros a 'nova Matemática', que, na maior parte das vezes, não era mais que uma nova extravagância, tão impossível de ensinar como de aprender e que, de 'Matemática', só tinha o nome (FREUDENTHAL, 1979, p. 321).

Para ele, o principal equívoco dos partidários da Matemática Moderna consistia em efetuar encurtamentos, com conceitos mais adiantados sendo ensinados na escola infantil. Assim, certos sistemas colocados a serviço de abstrações matemáticas, "desligados de seu sentido e do seu contexto matemáticos, considerados temas de estudo, concretizados de maneira absurda, eram ensinados a crianças de qualquer idade" (FREUDENTHAL, 1979, p. 318). 
Em oposição à concepção de Matemática como disciplina erudita cujo ensino é dispensado a todas as idades, Freudenthal (1968) entende matemática como uma atividade natural e social cuja evolução acompanha a do indivíduo e a das necessidades de um mundo em expansão.

Para Freudenthal (1979, p. 321), a

\begin{abstract}
Matemática é uma actividade humana simultaneamente natural e social, tal como a palavra, o desenho e a escrita. Figura entre as primeiras actividades cognitivas conhecidas e foi a primeira disciplina a ser ensinada, mas evoluiu e transformou-se sob a influência das modificações sociais, bem como a sua Filosofia e a maneira de ser ensinada.
\end{abstract}

Foi ele o fundador e diretor do IOWO (Institut Ontwikkeling Wiskunde Onderwijs - Instituto para o Desenvolvimento do Ensino da Matemática, Utrecht, Holanda), entre 1971, ano da fundação, até dezembro de 1980, quando o Instituto cessa suas atividades. Entretanto, parte das atividades continuou por meio do OW\&OC (Research Group on Mathematics Education and Educacional Computer Centre), sediado na Universidade de Ultrech, a partir de janeiro de 1981.

Van Den Heuvel-Panhuizen $(1996,2000)$ lembra-nos que o IOWO ofereceu as condições necessárias para o desenvolvimento do Wiskobas, projeto do CMLW (Mathematics Curriculum Modernization Committee) estabelecido pelo governo holandês em 1961 para modernizar a Educação Matemática nas escolas secundárias. Com seu início, atenções também se voltaram ao ensino primário por meio de outros projetos.

Embora os fundamentos desse projeto já tivessem sido iniciados por Wijdeveld e Goffree, foi Freudenthal, por sua resistência ao movimento da Matemática Moderna e aversão aos manuais escolares que estavam sendo exportados para a Holanda, quem deu o impulso inicial para o movimento de reforma da Educação Matemática, que ficou conhecido como Educação Matemática Realística. A razão pela qual a reforma foi chamada de realística diz respeito não apenas à conexão com o mundo real, mas principalmente à ideia de oportunizar aos estudantes situações que eles possam imaginar: é essa a tradução do verbo holandês zichREALISEren. É a ênfase dada em tornar algo real na mente dos estudantes que dá à RME esse nome.

Freudenthal $(1979$, p. 323) resume os conceitos fundamentais do IOWO, por meio de alguns slogans, dos quais destacamos:

- Matemática como atividade humana, ao invés de disciplina preestabelecida;

- matematização da realidade, ao invés de realidade já matematizada;

- reinvenção ao invés de transmissão de conceitos; 
- apresentação da realidade como fonte, a priori, da Matemática, ao invés de domínio de aplicação;

- articulação da Matemática com outros domínios, ao invés de apresentação isolada;

- contextos ricos de significado, ao invés de reunião de problemas de palavras;

- compreensão ao invés de mera reprodução de mecanismos.

Para ele, a Matemática nunca deve ser apresentada aos estudantes como um produto pronto e acabado; ao contrário, precisa ser conectada à realidade, próxima aos estudantes e relevante para a sociedade, a fim de tornar-se um valor humano. Nessa perspectiva, os estudantes devem ser tomados como participantes ativos do processo educacional. A eles devem-se propor situações que demandam organização matemática, da qual emergirão os conceitos; deve ser dada a oportunidade de reinventar a Matemática por meio de um processo de matematização da realidade.

Em linhas gerais, toma-se matematização como o processo de organização da realidade usando ideias e conceitos matemáticos. Conforme aponta-nos De Lange (1987, p. 37, tradução nossa), num primeiro momento uma situação ou problema do mundo real é explorado intuitivamente, o que significa "organizar e estruturar o problema, tentando identificar os aspectos matemáticos do problema, descobrir regularidades". Essa exploração inicial com um forte componente intuitivo pode levar ao desenvolvimento, descoberta ou (re) invenção de conceitos matemáticos.

Figueiredo (2000) aponta que, para Freudenthal, matematização é o processo-chave da atividade matemática por duas razões. Em primeiro lugar, porque, além de ser a atividade principal dos matemáticos, a matematização possibilita aos estudantes aproximar os conceitos matemáticos das situações de sua vida diária. Em segundo lugar, porque a Educação Matemática deve ser organizada como um processo de reinvenção guiada, em que a matematização oportuniza aos estudantes experimentar algo similar ao processo de desenvolvimento da própria Matemática enquanto ciência.

Na Educação Matemática tradicional, toma-se o resultado das atividades (formalização por meio da axiomatização) como ponto de partida para o ensino. Para Freudenthal, trata-se de uma inversão antididática. A Matemática deveria ser ensinada com a finalidade de ser útil. Porém, isso não "poderia ser realizado simplesmente ensinando uma 'matemática útil'; isso inevitavelmente resultaria em um tipo de matemática que é útil apenas em um conjunto 
limitado de contextos" (GRAVEMEIJER; TERWEL, 2000, p. 780, tradução nossa). Por isso, matemática deveria ser ensinada como matematizar.

Para Gravemeijer (2008), em contraste com a cultura tradicional de sala de aula, a proposta de reinvenção demanda uma cultura inquisitivo-orientada. Os estudantes têm que trabalhar como uma comunidade de aprendizes, adotando como normas sociais a obrigação de explicar e justificar suas soluções. Espera-se que eles tentem entender os raciocínios dos outros estudantes, e façam perguntas, se não entenderem; e argumentem, se não concordarem.

Além disso,

a orientação tanto de professores quanto de livros didáticos não só é necessária para garantir que a matemática que os alunos inventam tenha correspondência com a Matemática convencional, mas também para que reduza substancialmente o processo de invenção. Os estudantes não podem simplesmente reinventar a matemática que os mais brilhantes matemáticos demoraram muito tempo para desenvolver. Os professores precisam ajudar os estudantes constantemente, enquanto tentam se certificar que os estudantes experienciem seu aprendizado como um processo de ‘invenção’ (GRAVEMEIJER, 2008, p. 285, tradução nossa).

Um importante papel é assumido pelo professor nesse processo, já que é ele quem conduz diariamente as observações, aplica testes, diagnostica e intervém. A fim de apoiar esse processo de reinvenção guiada, as tarefas propostas devem proporcionar ao professor o máximo de informação do conhecimento, dos insights e das habilidades do seu estudante.

Como um ponto especial de atenção, podemos notar que a reinvenção apresenta tanto aspectos individuais quanto coletivos, e é a interação entre estudantes, em particular, que funciona como um catalisador. O professor precisa desenvolver tarefas que possibilitem uma variedade de respostas pelos estudantes (GRAVEMEIJER, 2008, p. 289, tradução nossa).

O professor deve identificar situações que possam ser utilizadas para explorar estratégias informais dos estudantes e, portanto, como pontos de partida para o processo de reinvenção. Freudenthal sugere olhar para aplicações em que se possam encontrar fenômenos a serem organizados por conceitos, procedimentos e ferramentas matemáticas (fenomenologia didática). Assumindo "que a matemática emerge como resultado da resolução de problemas práticos, podemos presumir que as aplicações diárias englobam um fenômeno, que originalmente tem que ser organizado" (GRAVEMEIJER, 2008, p. 290). Consequentemente, devem ser analisadas aplicações diárias objetivando encontrar pontos de partida para elaborar propostas de rotas de reinvenção.

\section{Acerca da avaliação em RME}


O trabalho de De Lange (1987) descreve a introdução na Holanda de um novo currículo para o nível secundário, a Matemática $A$, voltado para estudantes que se preparavam para cursos superiores de humanidades e ciências sociais e econômicas. Esse currículo, desenvolvido entre os anos de 1981 e 1985 por pesquisadores do OW\&OC, foi considerado por muitos como uma revolução por romper com aspectos da educação tradicional.

$\mathrm{O}$ autor apresenta os principais aspectos do currículo Matemática $A$ operacionalizados no desenvolvimento de materiais didáticos experimentais, e um dos pontos destacados é o importante papel atribuído aos contextos, já que esses possibilitam que qualquer tópico seja iniciado por meio de situações realísticas, não restritas ao mundo físico ou social, mas incluindo situações imagináveis que possam servir ao desenvolvimento de conceitos matemáticos. Um dos objetivos mais importantes diz respeito à preocupação com o desenvolvimento da habilidade de matematizar.

Ao apresentar os resultados da pesquisa feita junto aos estudantes e professores das primeiras escolas onde se implantou a Matemática $A$, aponta que um dos problemas observados diz respeito ao modo como a avaliação vinha sendo feita. $\mathrm{O}$ uso de provas escritas com tempo limitado não possibilitava avaliar, de forma satisfatória, objetivos da Matemática $A$ como a matematização, a reflexão, a inventividade e a criatividade. Tornou-se necessário pensar novas formas de avaliação.

Isso porque, em RME, a avaliação é tomada como parte integrante e indissociável do processo de ensino e a própria educação deve ser vista como um processo permanente de avaliação, de modo que as atividades de ensino e de avaliação "andem de mãos dadas". Uma avaliação condizente com a RME deve, como a educação, tomar a Matemática enquanto atividade humana. Deve levar em conta que, em seu processo de desenvolvimento, os estudantes passam por diversos níveis de matematização e "criam" sua própria matemática.

Enquanto ensinam, os professores precisam saber a respeito dos problemas de aprendizagem de seus estudantes, seus progressos e o nível de formalidade com que estão operando. Eles podem encontrar essa informação por uma variedade de modos, incluindo, por exemplo, observações e discussões das tarefas e projetos propostos, lições de casa, autoavaliação e apresentações orais.

Quando os resultados obtidos são utilizados para adaptar os processos de ensino, fala-se em avaliação didática ou formativa. Em linhas gerais, a avaliação é didática quando "tem por intenção respaldar os processos de ensino e de aprendizagem" (VAN DEN HEUVELPANHUIZEN, 1996, p.2, tradução nossa ${ }^{1}$ ), o que nos leva a considerar suas finalidades, seu conteúdo, seus métodos e os instrumentos utilizados tendo natureza didática.

1 "This is assessment that is intended as a support to the teaching and learning process". 
Sua finalidade é coletar dados dos estudantes e de seus processos de aprendizagem, a fim de tomar decisões educacionais, que podem envolver decisões mais simples a respeito de tarefas de ensino, ou decisões mais amplas, como, por exemplo, se os estudantes precisam de assistência suplementar, se se deve ou não introduzir algo novo, como abordar um determinado componente do programa, e ainda, questões relativas à aprovação ou reprovação.

A natureza didática dos métodos de avaliação envolve a integração entre ensino e avaliação, o que significa que a avaliação deve desempenhar algum papel em cada fase dos processos de ensino e de aprendizagem, tanto "olhando para trás" (ou seja, determinar o que os estudantes aprenderam) quanto "para frente" (produzir informações para ações futuras).

Em seu trabalho Framework for classroom assessment in mathematics, De Lange (1999) apresenta-nos um "esboço" para avaliação em Matemática, listando nove princípios que devem nortear o trabalho do professor que "leva a sério" a avaliação:

1. o objetivo principal da avaliação escolar deve ser a aprendizagem;

2. a matemática deve estar imersa em problemas que sejam realísticos e "valham a pena";

3. os métodos de avaliação devem permitir que os estudantes revelem mais aquilo que sabem ao invés do que não sabem;

4. a avaliação deve ser balanceada e incluir múltiplas e variadas oportunidades para os estudantes mostrarem e documentarem suas realizações;

5. as tarefas de avaliação devem operacionalizar todas as metas do currículo;

6. os critérios de classificação devem ser públicos e consistentemente aplicados;

7. o processo de avaliação, incluindo os critérios de pontuação e classificação, deve ser acessível aos estudantes;

8. os estudantes devem ter oportunidade de receber feedback do seu trabalho;

9. a qualidade de uma tarefa deve ser definida por características como autenticidade e equidade.

Essa lista de princípios toma como meta capacitar os estudantes a lidarem com a Matemática envolvida em problemas do mundo real, representar, formular e resolver problemas intra e extra matemáticos, presentes em uma variedade de domínios e configurações. Em outras palavras, contribuir para que os estudantes tornem-se matematicamente letrados. 
Letramento matemático é uma capacidade do indivíduo em identificar e compreender o papel que a matemática desempenha no mundo, de fazer julgamentos bem fundamentados, e de usar a matemática de modo a atender as suas necessidades presentes e futuras enquanto cidadão construtivo, interessado e reflexivo (DE LANGE, 2003, p.76, tradução nossa).

O letramento matemático não pode ser reduzido ao conhecimento de terminologias matemáticas, fatos e procedimentos, nem mesmo na aquisição de habilidades para realização de operações ou aplicação de certos métodos. Ao contrário disso, deve ser pensado como um "espectro contínuo", em que o conhecimento matemático seja colocado em uso funcionalmente, em uma multiplicidade de contextos.

Assim, os conteúdos de avaliação não podem estar restritos a habilidades isoladas, mas, ao contrário, toda uma gama de metas deve ser coberta, tanto em extensão (todos os componentes curriculares e as ligações entre eles) como em profundidade (todos os níveis de competências).

\section{As tarefas de avaliação}

Quando almejamos obter um panorama o mais completo possível dos processos de matematização dos estudantes, a avaliação deve envolver o uso de uma extensa variedade de instrumentos para recolha das informações. Exceto por sua finalidade específica, os instrumentos de avaliação são muitas vezes indistinguíveis daqueles utilizados pelo professor para iniciar certos processos de aprendizagem. O importante é que possibilitem, na medida do possível, expor os processos de aprendizagem e forneçam um repertório das habilidades, conhecimentos e insights dos estudantes em um dado momento.

Para fazer Matemática, é necessário recorrer simultaneamente a muitas habilidades, que não podem ser avaliadas independentemente. De Lange (1999) organiza em três níveis as competências a serem mobilizadas na resolução de tarefas matemáticas.

Os itens de tarefas de Nível I envolvem conhecimentos de fatos e representações, reconhecimento de equivalências, recordação de objetos matemáticos e propriedades, realização de procedimentos de rotina, aplicação de algoritmos padrão e desenvolvimento de habilidades técnicas.

As tarefas de Nível II exigem que o estudante comece a fazer conexões entre diferentes vertentes e domínios da Matemática e a integrar informações para resolver problemas simples em que se deve fazer escolha de estratégias e se utilizar ferramentas matemáticas. Espera-se também que lide com diferentes formas de representação, e que seja capaz de distinguir e relacionar diferentes elementos matemáticos (definições, exemplos, provas). 
Por fim, no Nivel III, o estudante deve matematizar situações, analisando, interpretando, desenvolvendo seus próprios modelos e estratégias e apresentando argumentos matemáticos, incluindo provas e generalizações. Esse último nível incorpora habilidades e competências normalmente associadas com os outros dois níveis, mais difíceis de serem avaliadas.

Os três níveis de competências mobilizadas em tarefas matemáticas podem ser visualmente representados em uma pirâmide, mostrada na Figura 1 (versão traduzida ${ }^{2}$ do original apresentado por De Lange (1999)). Além dos três níveis, outros dois aspectos são mostrados no esquema: os quatro "grandes domínios" da Matemática (Álgebra, Geometria, Aritmética e Probabilidade e Estatística), e o nível de dificuldade das questões (que vão, continuamente, do simples ao complexo, ou do informal para o formal).

Figura 1: Pirâmide de avaliação proposta por De Lange (1999).

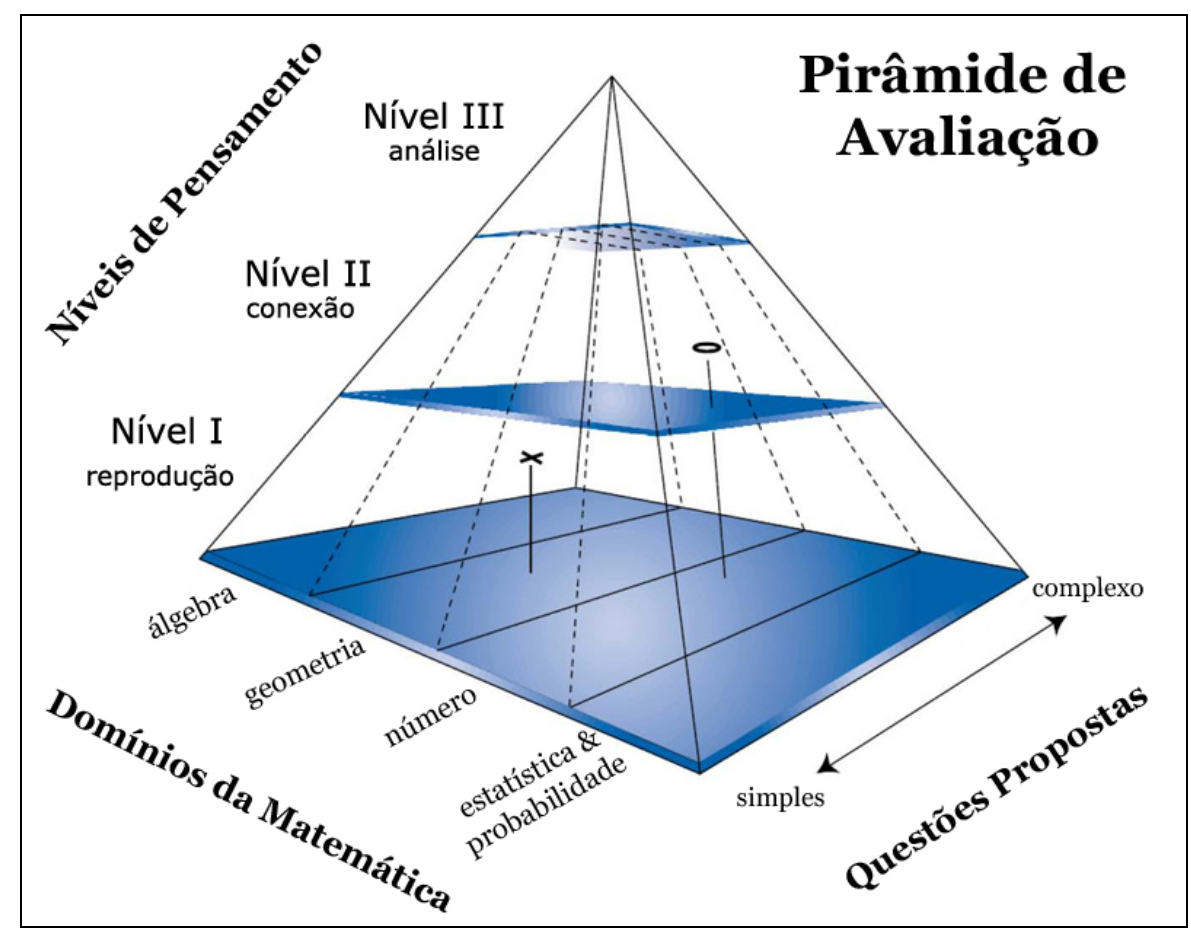

Fonte: Ferreira (2012).

Qualquer tarefa de avaliação pode ser localizada na pirâmide. Além disso, dado

que a avaliação deve medir e descrever o crescimento do estudante em todos os domínios da Matemática e em todos os três níveis de pensamento, as questões em um programa de avaliação completo devem preencher a pirâmide. Devem existir questões em todos os níveis de competência, de diferentes graus de dificuldade e em todos os domínios de conteúdo (DE LANGE, 1999, p.17, tradução nossa). 
Na mesma direção apontada por De Lange (1999), Shannon (1999) fala em três categorias de organização do conhecimento matemático envolvido nas tarefas de avaliação: habilidades matemáticas, entendimento conceitual e resolução de problemas matemáticos. A primeira categoria contempla questões que objetivam avaliar o conhecimento de fatos e algoritmos, demandando pouco ou nenhum conhecimento conceitual dos estudantes.

Tarefas que requeiram que o estudante use, represente ou mesmo explique certo conceito são classificadas na segunda categoria. Para a autora, "boas tarefas de entendimento conceitual não podem ser resolvíveis por meio de uma matemática inerentemente frágil e composta por 'lascas' descontextualizadas e fragmentadas do conhecimento matemático" (SHANNON, 1999, p.16, tradução nossa). A resolução de uma tarefa desse tipo não é totalmente isenta do uso de procedimentos, porém as representações simbólicas requeridas superam "de longe" a simples manipulação algorítmica.

$\mathrm{Na}$ última categoria temos tarefas que requeiram dos estudantes: selecionar uma abordagem adequada para a situação (que deve ser apresentada de forma pouco estruturada e sem instruções diretas); selecionar procedimentos, conceitos e estratégias necessários, e adotá-los na busca de uma solução; e por fim esboçar algum tipo de conclusão. Segundo a autora, uma avaliação balanceada deve conter questões que contemplem esses três aspectos do conhecimento matemático. Lembra-nos também que esse tipo de classificação, embora baseado em propriedades da tarefa, apresenta fronteiras pouco definidas entre as categorias e nem mesmo se tratam de conceitos mutuamente excludentes.

Apesar das diferentes nomenclaturas, reconhecemos uma relação direta entre os níveis propostos por De Lange (1999) e as categorias apresentadas por Shannon (1999). Questões no Nivel I avaliam habilidades matemáticas de reprodução, questões no Nível II focam em compreensão conceitual e questões do Nivel III envolvem a resolução tarefas que Shannon (1999) caracteriza como problemas matemáticos.

Segundo Van Den Heuvel-Panhuizen (1996), além da natureza didática da avaliação, é crucial o papel desempenhado pelas tarefas ou problemas escolhidos para avaliação. Em oposição às preocupações puramente psicométricas, “o que” está sendo perguntado é, para a autora, mais importante do que o formato da tarefa ou o instrumento utilizado. As tarefas ou problemas de avaliação devem ser vistos como situações que requerem uma solução, que possam ser organizadas e esquematizadas (em suma, situações que possam ser matematizadas). 
Como a RME baseia-se na ideia de Matemática enquanto atividade humana, as situações propostas devem ser bastante familiares para os estudantes e oferecer-lhes oportunidades para a matematização. Devem aprender a analisar, organizar e aplicar Matemática de forma flexível em situações que sejam significativas para eles, e os problemas devem ser acessíveis, convidativos, e que "valham a pena" serem resolvidos ${ }^{3}$. Também devem ser desafiadores, deixando claro para os estudantes por que algo está sendo perguntado.

Assim, a resolução de problemas na RME não significa simplesmente realizar um procedimento fixo, mas propor problemas que possam ser resolvidos de formas diferentes. Os estudantes deverão desempenhar um papel ativo na construção de seu próprio conhecimento matemático. O ensino e a avaliação devem ser planejados de modo que o professor possa chegar o mais próximo possível do conhecimento informal dos estudantes, para que então possa ajudá-los a alcançar um maior nível de compreensão guiado pela reinvenção.

A fim de apoiar este processo de reinvenção guiada, os problemas devem proporcionar ao professor o máximo de informação do conhecimento, dos insights e das habilidades de seus estudantes. Deve também haver espaço para as construções dos próprios estudantes, o que significa que os problemas devem poder ser resolvidos por diferentes estratégias e em diferentes níveis. Desta forma, os problemas devem ser capazes de tornar o processo de aprendizagem transparente para ambos: os professores e os estudantes.

Os estudantes são participantes ativos e, como tal, devem também receber feedback de seu progresso de aprendizagem. Além disso, os problemas devem possibilitar aos estudantes demonstrar o que sabem mais do que simplesmente revelar o que ainda não sabem. Para a autora, "bons problemas de avaliação em RME têm muito em comum com bons problemas de ensino" (VAN DEN HEUVEL-PANHUIZEN, 1996, p. 91, tradução nossa).

Outra característica marcante em RME é o importante papel desempenhado pelos contextos nos problemas de avaliação. Seja referindo-se às situações da vida cotidiana, às situações fantasiosas, ou mesmo aos chamados problemas "nus", o importante é que os contextos apresentem situações apropriadas para a matematização, na qual os estudantes sejam capazes de imaginar algo e fazer uso de suas próprias experiências e conhecimento.

A autora apresenta algumas das principais funções dos contextos em problemas de avaliação:

\footnotetext{
3 “[...] the problems must therefore be accessible, inviting, and worthwhile solving".

${ }^{4}$ Expressão usada para caracterizar problemas em cuja formulação utiliza-se de uma linguagem puramente matemática.
} 
- potencializar a acessibilidade: além de tornar as situações "reconhecíveis" e facilmente imagináveis, os contextos podem propiciar um ambiente agradável e convidativo, potencializando a acessibilidade ao problema;

- ampliar o alcance e transparência dos problemas: comparados à maioria dos problemas "nus", os problemas de contexto oferecem aos estudantes mais oportunidade para demonstrar suas habilidades. Se o problema puder ser resolvido em diferentes níveis, sua elasticidade é aumentada, reduzindo o caráter de "tudo ou nada" da avaliação;

- incitar estratégias: este papel de provedor de estratégias viabiliza o objetivo fundamental da RME, a capacidade de resolver um problema por meios matemáticos próprios e insights.

Baseando-se em uma vasta literatura, Van Den Heuvel-Panhuizen (1996, 2003, 2005), apresenta uma visão geral das características de "bons" problemas de avaliação. Dentre elas, destacamos algumas:

- os problemas precisam ser significativos e "valer a pena": precisam ser matematicamente interessantes e cativantes. Para alguns autores, um problema é uma situação em que nenhum método de solução pronto está disponível, enquanto outros pensam que o estudante precisa ter uma razão para resolver o problema. Além disso, problemas significativos não precisam necessariamente ser diretamente relevantes ou práticos, mas precisam ser atraentes e estimulantes para os estudantes.

- problemas matematicamente interessantes são principalmente aqueles em que mais de uma resposta correta é possível, além de ter certo grau de complexidade. Além disso, bons problemas devem exigir mais do que lembrar de um fato ou a reprodução de uma habilidade, ter alguma componente educativa (tanto estudantes quanto professores vão aprender com a tentativa de respondê-los) e devem ser abertos (o que significa que várias respostas podem ser possíveis).

- os problemas devem elucidar o conhecimento a ser avaliado: devem fornecer informações do conhecimento que os estudantes possuem, e 
expressar o máximo possível o quanto assimilaram desse conhecimento e o quanto podem aplicá-lo em novas situações.

- os problemas devem revelar algo dos processos de aprendizagem dos estudantes: é importante que incitem certas estratégias, exponham as técnicas de solução adotadas pelos estudantes e revelem algo subjacente ao processo de resolução.

No que diz respeito às provas escritas, a autora lembra-nos que, essa pode ser interpretada e vista tanto como um instrumento de certificação quanto como um instrumento de orientação, dependendo do uso que o professor faça dele. Apesar de suas potencialidades, Van Den Heuvel-Panhuizen (1996, p. 133) aponta que, na maioria dos casos, as questões propostas nas provas escritas de Matemática concentram-se unicamente em habilidades simples, ignorando situações que exigem o estabelecimento de conexões ou mesmo oportunizem a matematização, não fornecendo informações completas das estruturas de conhecimento dos estudantes.

Para essa autora, é fundamental explorar as potencialidades desse instrumento, e a título de exemplo discorre acerca de alternativas às tradicionais provas escritas. Além da escolha de questões que contemplam características já mencionadas, outros formatos são possíveis para a prova escrita.

\section{Considerações finais: a RME como "inspiração" para repensar o ensino e a avaliação em Matemática}

Um dos formatos diferenciados para prova escrita é a chamada prova em duas fases, presente em projetos de desenvolvimento do novo currículo para o nível secundário na Holanda. Segundo De Lange (1987), a primeira metade da prova contém questões abertas, e na segunda metade há questões do tipo "ensaio" . A primeira fase é encaminhada como uma prova escrita tradicional: os estudantes devem responder tantas questões quanto possível num espaço de tempo limitado. Espera-se que respondam principalmente as questões abertas da primeira parte. Numa segunda fase, a prova é devolvida aos estudantes com comentários do professor e, de posse delas, o estudante complementa o trabalho em casa, podendo responder as

\footnotetext{
5 "Essay question" corresponde a um item ou uma tarefa em que se propõe ao estudante discorrer a respeito de um tema, como, por exemplo (Van de Heuvel-Panhuizen, 1996), escrever uma resposta para um artigo de jornal ou emitir um parecer acerca de um problema da vida quotidiana.
} 
questões da maneira que escolher: independente uma das outras, ou na forma de um ensaio. Após o tempo combinado (algumas semanas, por exemplo), a prova é devolvida e novamente corrigida pelo professor.

Para o autor, a correção e pontuação na primeira fase é relativamente objetiva, pois em geral envolve respostas curtas de construção fechada. A segunda fase, por sua vez, é considerada mais trabalhosa, uma vez que questões do tipo "ensaio" dão aos estudantes a oportunidade de mostrar aquilo que sabem, gerando uma variedade de produções, desde respostas diretas até verdadeiros "livros". Na proposta do uso desse instrumento, a segunda fase não é vista como uma segunda chance, mas como um meio para "forçar o estudante a refletir a respeito da sua primeira fase" (DE LANGE, 1987, p.207, grifo do autor, tradução nossa).

O contato inicial com as ideias da RME e com a prova em duas fases "inspiraram" o desenvolvimento da tese de doutorado do primeiro autor deste texto (NOME DO PRIMEIRO AUTOR, 2013), sob orientação da segunda autora. A partir da leitura de alguns relatos que descreviam experiências similares àquela que se pretendia desenvolver, selecionamos um rol de questões típicas, provenientes de livros didáticos e provas aplicadas em anos anteriores, organizamos a prova (a ser desenvolvida em seis fases, todas em sala de aula e contemplando o conteúdo previsto para um semestre letivo) e "partimos para campo". A proposta, inicialmente pensada como uma espécie de "piloto", foi desenvolvida em aulas de Matemática em uma turma de segundo ano do Ensino Médio.

Ao elaborar a prova em fases, propiciando aos estudantes resolvê-las ao longo de um semestre, alterando suas resoluções sempre que julgassem necessário, imaginávamos estar tomando a avaliação como uma prática de investigação e oportunidade de aprendizagem. Porém, ao buscar na literatura algum referencial que sustentasse nossa prática avaliativa, pudemos perceber uma série de "falhas" tanto na elaboração quanto na implementação do instrumento.

Embora tivéssemos modificado o instrumento, as questões que o compuseram e, mais do que isso, a própria atitude frente a ele continuavam "tradicionais". Se, por um lado, a experiência pontual de utilização da prova em fases nessas turmas não pode ser tomada como uma prática de avaliação, na perspectiva de ser formativa para os estudantes, foi inegável seu potencial formativo para mim, enquanto professor.

Além de repensar o instrumento, ficou evidente a necessidade de repensar a própria prática avaliativa, numa busca constante de completá-la, modificá-la e aperfeiçoá-la (BARLOW, 
2006). Ao trazer para mim essa tarefa, numa busca de melhorar meu próprio trabalho enquanto avaliador, reconheci-me não apenas como um investigador da própria prática (segundo Ponte (2002), aquele que estuda não um objeto qualquer, mas certo aspecto da sua prática profissional), mas como alguém que investigou a própria prática avaliativa.

A utilização da prova em fases colocou "em xeque" esse modelo de avaliação na qual os estudantes já estavam moldados. Afinal, a prova já era conhecida. Assim como eles sentiamse desconfortáveis com esse fato, pois não sabiam bem como estudar para uma prova que já conheciam, eu acabava por orientar minhas aulas com vistas a "prepará-los" para resolver a prova.

A possibilidade de fazer e refazer as questões quantas vezes fossem necessárias, oportunidade genuína quando se fala em feedback num contexto de avaliação formativa, mostrou-se bastante limitada naquele momento. Por um lado, uma releitura das questões da prova, propiciada por meio da análise da produção escrita dos estudantes, mostrou que os questionamentos que eu havia apresentado ao lado de suas resoluções eram bastante limitados, e em pouco contribuíram na direção de possibilitar reconhecer e corrigir seus erros. O aprimoramento dessa "arte de fazer perguntas" deve ser um exercício constante na prática do professor que busca tornar a avaliação uma oportunidade de aprendizagem.

Por outro lado, a escolha das questões que compuseram a prova dificultou a elaboração de questionamentos que levassem os estudantes a refletir a respeito de suas resoluções. Um olhar mais cuidadoso mostrou que uma minoria delas apresenta características de "bons" problemas de avaliação. Desse modo, muitas vezes dificultavam, ou mesmo limitavam, as possibilidades de intervenção por meio de questionamentos. Praticamente envolviam estratégias e procedimentos limitados à memorização e reprodução de algoritmos vistos em aula, tolhendo qualquer possibilidade dos estudantes mostrarem-se como sujeitos ativos de seus processos de aprendizagem.

Além disso, a própria imposição de um contrato de trabalho no que concerne à utilização do instrumento de avaliação contribuiu para o sentimento de "fracasso". Não houve nenhum tipo de negociação com os estudantes no sentido de combinar procedimentos para a realização da prova em fases. As regras vieram prontas e, enquanto professor, não me permiti alterá-las mesmo tendo percebido que as coisas não estavam "andando bem".

O estabelecimento de um contrato de avaliação não significa que o professor ficará simplesmente à mercê da vontade dos estudantes. Implica, sim, em explicitar as "regras do 
jogo", nas palavras de Hadji (1994). A simples informação de que as questões não seriam corrigidas ao fim da terceira etapa (no sentido de apontar quais estavam certas ou não) possivelmente teria evitado uma série de momentos de stress sentidos ao longo da prova. Além disso, a clareza dos critérios de avaliação adotados poderia ser uma dose de motivação para que os estudantes buscassem refletir a respeito dos questionamentos ao longo de suas resoluções. Pensar a avaliação não só em sua função certificadora, mas também em suas perspectivas orientadora e reguladora requereu ir além de verificar se os estudantes dominavam certo conhecimento para buscar alternativas com vistas a guiá-los constantemente em seus processos de aprendizagem.

$\mathrm{Na}$ perspectiva de contribuir para que os estudantes tornem-se matematicamente letrados, tornam necessária uma discussão tanto em relação a métodos diferentes de avaliação quanto aos

\begin{abstract}
conteúdos considerados básicos ou mínimos para cada uma das séries ou ciclos e que se encontram presentes nos inúmeros programas das secretarias dos ensinos municipal e estadual [...] ou, ainda aqueles presentes nos inúmeros planos de curso de professores e professoras das redes pública e privada de todo o país que, não esporadicamente, orientam suas práticas educativas priorizando e avaliando os conteúdos sugeridos no livro didático adotado (OLIVEIRA; PACHECO, 2008, p. 124).
\end{abstract}

Segundo esses autores, faz-se necessária uma reflexão em torno das questões curriculares e também em relação às tendências de mudanças dos mecanismos e instrumentos clássicos de avaliação. Mitos e ritos (BARLOW, 2006) que circunscrevem o contexto escolar, mostram-se com frequência presentes no contexto educacional, interferindo fortemente na "criação" de currículos de Matemática e muitas vezes impedindo que professores vislumbrem possibilidades efetivas de repensá-los e de reorientar suas práticas pedagógicas.

\title{
Agradecimentos
}

CNPq, Fundação Araucária (conv. 386/2012).

\section{Referências}

BARLOW, M. Avaliação escolar: mitos e realidades. Porto Alegre: Artmed, 2006.

DE LANGE, J. Mathematics, Insight and Meaning. Utrecht: OW \&OC, 1987.

Framework for classroom assessment in mathematics. Utrecht: Freudenthal Institute and National Center for Improving Student Learning and Achievement in 
Mathematics and $\quad$ Science, $1999 . \quad$ Disponível em: $<$ http://www.fi.uu.nl/publicaties/literatuur/6279.pdf $>$. Acesso em: 12 jun. 2010.

. Mathematics for Literacy. In: MADISON, B. L.; STEEN, L. A. (Eds). Quantitative Literacy: Why Numeracy Matters for Schools and Colleges. Princeton, New Jersey: National Council on Education and the Disciplines, 2003, p. $75-89$.

FERREIRA, P. E. A. Enunciados de tarefas de Matemática: um estudo sob a perspectiva da Educação Matemática Realística. 2013. Tese (Doutorado em Ensino de Ciências e Educação Matemática) - Universidade Estadual de Londrina, Londrina.

FERREIRA et al. Inventário de trabalhos a respeito da Educação Matemática Realística. In: V SEMINÁRIO INTERNACIONAL DE PESQUISA EM EDUCAÇÃO MATEMÁTICA, 2012, Petrópolis. Anais... Petrópolis: SBEM, 2012. Disponível em: <http://sipemsbem.lematec.net/CD/PDFs/GT08/CC04864914982_A.pdf>. Acesso em: 26 dez. 2013.

FIGUEIREDO, N. Realistic Mathematics Education: a different approach to learning and instruction. Quadrante, Lisboa, v.9, n.1, p. 87-107, 2000.

FREUDENTHAL, H. Why to Teach Mathematics so as to Be Useful. Educational Studies in Mathematics, v. 1, n. 1-2, p. 3-8, 1968. 1979 .

Matemática nova ou educação nova? Perspectivas (Portugal), v. 9, n.3, p. 317-328,

GRAVEMEIJER, K. RME theory and mathematics education. In: TIROSH, D.; WOOD, T. (Eds). Internacional handbook of mathematics education: Vol.1. Knowledge and beliefs in mathematics teaching and teaching development. Rotterdam, The Netherlands: Sense Publishers, 2008, p. $283-302$.

GRAVEMEIJER, K.; TERWEL, J. Hans Freudenthal: a mathematician on didactics and curriculum theory. Journal of Curriculum Studies, Basingstoke, v. 32, n. 6, p. 777-796, 2000 .

HADJI, C. A avaliação, regras do jogo. 4.ed. Portugal: Porto, 1994.

OLIVEIRA, I.B. de; PACHECO, D. C. Avaliação e currículo no cotidiano escolar. In: ESTEBAN, M. T. Escola, currículo e avaliação. 3.ed. São Paulo: Cortez, 2008. p. 119-136.

PONTE, J. P. Investigar a nossa própria prática. In: GTI (Org.). Reflectir e investigar sobre a prática profissional.. Lisboa: APM, 2002. p.5-28.

SHANNON, A. Keeping score. National Research Council: Mathematical Sciences Education Board. Washington, DC: National Academy Press, 1999.

TREVISAN, André Luis. Tese de doutorado, 2013.

VAN DEN HEUVEL-PANHUIZEN, M. V. D. Assessment and Realistic Mathematics Education. Utrecht: CD-ß Press/Freudenthal Institute, Utrecht University. 1996. 
. Mathematics education in the Netherlands: a guided tour. Freudenthal Institute Cdrom for ICME9. Utrecht: Utrecht University, 2000.

The didactical use of models in realistic mathematics education: an example from a longitudinal trajectory on percentage. Educational Studies in Mathematics, v. 54, n. 1, p. $09-35,2003$.

. The role of contexts in assessment problems in mathematics. For the Learning Mathematics, v. 25, n. 2, p. 2 - 9, 2005. 